\title{
Discussion
}

Mr Isaac, introducing the Paper, said it was important to emphasize that the apparent reduction in the concentration of alkyl-benzene-sulphonate from inlet to outlet of the biological filters was not to be taken as a measure of the destruction of the detergent, if by "destruction" was understood its breakdown to relatively simple inorganic compounds.

90. Professor C. N. Sawyer, of the Massachusetts Institute of 'Technology, in a personal communication, had shown that polypropylene-benzene-sulphonate could be, to a certain extent, oxidized by acclimatized sewage organisms. It had been well established that the oxidation was not complete, since the sulphonate groupe of the detergent had not been recovered as inorganic sulphate. (That contrasted with experience obtained with alkylbenzene-sulphonates not derived from propylene.) Professor Sawyer had shown that, where the benzene ring was attached to the alkyl group at a tertiary carbon atom, complete aerobic biological oxidation to simple inorganie substances was blocked, to leave a relatively complex end-product. He had further shown by infra-red spertroscopy that the benzene ring in alkyl-benzene-sulphonates derived from propylene was attached mainly at tertiary carbon atoms in the alkyl group.

91. The intermediate and final products of the oxidation were probably almost as significant in producing foam, and some other effects of surface activity, as the original agent. They had, however, less tendency to form a complex with methylene blue than the original alkyl-benzene-sulphonate. Sawyer had shown that, whereas $99 \%$ of the alkyl-benzene-sulphonate was extracted with chloroform in the presence of methylene blue, only $54 \%$ of sulphonated phenyl-undecanoic acid and only $10 \%$ of tertiary amyl-benzenesulphonate were so extracted. The undecanoic acid was similar to the probable primary oxidation product, and the sulphonate was rather similar to the end-product.

92. It seemed clear, therefore, that however satisfactory the chloroform extraction of a methylene-blue complex might be for the determination of an anionic detergent, it was less than satisfactory for the analysis of the products of the biological breakdown of those agents.

93. It had been shown at a number of sewage-treatment plants, e.g., at Mogden, ${ }^{21}$ that the presence in the sewage of an average concentration of less than 10 p.p.m. of anionic detergent had produced a significant deterioration in the quality of the effluent. Such deterioration would normally be accompaned by an appreciable quantity of detergent in the effluent. Where the capacity for self-purification of the receiving water was fairly heavily taxed, the combination of an increased B.O.D. load and the presence of detergent in the effluent might have decisive effects. Experiments carried out at the Water Pollution Research Laboratory ${ }^{22}$ showed that comparatively low concentrations of surface-active agent could substantially reduce the uptake of oxygen at the water surface. If the water was stagnant, or was very turbulent, the reduction was small. For intermediate degrees of turbulence, however, such as might be expected for many small lowland streams, as little as 0.1 p.p.m. of surface-active agent might reduce the oxygenuptake by more than $50 \%$. Dr Southgate ${ }^{23}$ concluded that "it seems likely that part at least of the deterioration in the condition of the [Thames] estuary in recent years is due to the introduction of surface-active agents".

94. The filters used in the experiments reported in the Paper were inside the College buildings and were, therefore, less subject to changes of temperature and other adverse effects of weather. In addition, the sewage was added at an almost constant rate, instead of varying over the day, week, and year. As a result, it was likely that the effects of the stated average concentrations of synthetic detergent were less than would oceur with full-scale open-air filters.

95. Hammerton ${ }^{24}$ had shown, in an interesting series of experiments, that the structure of the detergent molecule largely governed the ease, or otherwise, with which it was

21 References 21 et seq. are given on p. 405. 
biologically degraded. A straight-chain molecule was relatively easily broken down, and a branched chain was much less easily attacked. It appeared that the majority of alkylaryl-sulphonates in most common use as domestic detergents had branched structures and so were resistant to biological stabilization. It was unlikely, too, that it would be simple to avoid producing a branched-chain structure in a large proportion of the detergent molecules manufactured from the $\mathrm{C}_{12}$ to $\mathrm{C}_{18}$ alkyl hydrocarbons commonly used.

96. The prognosis was gloomy unless it was possible to persuade the user and manufacturer of synthetic detergents to accept a compound that was less effective as a detergent but more easily converted during sewage treatment. In that respect it was possible that the sucrose esters, whose manufacture was now under active investigation in the United States, might provide a satisfactory compromise.

Mr G. B. Townend (Chief Engineer, Middlesex County Main Drainage Department) said that much research and investigation had been carried out on synthetic detergents, both in the United Kingdom and in America; the Authors had reviewed only a small part alongside the results of their own experiments which largely confirmed those of earlier workers. They had stated their research was only on the effects of synthetic detergents on the biological oxidation of sewage; that was wise for the work in question because it should reach the heart of the problem. Other adverse effects were foaming on the purification plant and the discharge of much surface-active materials through the sewage works, leading to foaming and other troubles in the river. If, as the Authors had recognized, synthetic detergents were properly oxidized in the biological plant, there would neither be foaming at the sewage works, nor trouble in the rivers. Fundamentally the problem arose because the plant could not properly deal with detergents.

98. The Authors stated in $\$ 1$ that many sewage-treatment plants in Britain were overloaded, and the resultant ill effects had been intensified by increasing use of synthetic detergents. That was true. However, the Paper seemed to imply that most works were overloaded, and were that not so there would be no difficulties with detergents generally. If that were the Authors' intention he could not aecept it. Many works that would now normally have been operating satisfactorily were less efficient because of synthetic detergents.

99. "Overloading" was a relative term. It could be caused either by increasing the load until the plant could no longer accept it, or by causing a retardation in the oxidation processes resulting in loss of plant efficiency. Many works now showed both effects simultaneously; he thought the Authors had assumed that was the general case. However, in many plants, including Mogden, the only adverse factor had been detergents and not overloading in the ordinary sense.

100. The difficulty of sorting out the various effects had always been recognized and had been fully dealt with in the Report of the Committee on Synthetic Detergents. ${ }^{2}$ There did not exist two identical sewage works with the same flows and loadings, in one of which the sewage contained synthetic detergents and the other did not. It was not possible today to obtain a detergent-free sewage to act as a control, as the Authors had found. Although laboratory work could be kept under stricter control it could not reproduce all the conditions of a sewage plant, as he thought that the Authors had recognized. Sewage in practice varied considerably in volume and strength from day to day -oven from hour to hour-so that the concentration of synthetic detergent was also variable and figures based on national averages might be much exceeded at some places or at some times. Therefore, whilst laboratory work could provide useful pointers it could not replace the results of full-scale plants in actual operation. In practice evidence was now accumulating that the increasing use of synthetic detergents was accompanied by a corresponding fall in plant efficiency.

101. The earlier work of Hurley and others had been based on detergents of the alkylsulphate type, which, as the Authors had shown, could be biologically oxidized and removed from the effluent; they caused little trouble at normal concentrations. That did not apply to alkyl-aryl-sulphonates and they were used on a scale at present about four times greater than the earlier materials. 
102. The Authors had referred to the experience at Mogden; Mr Townend added details since he thought the results had not been published, although the Report of the Committee 2 had mentioned them. The Mogden plant had first operated towards the end of 1935 and had attained a highly nitrified effluent early in 1936. That had continued for about 14 years, until 1950. The plant had operated consistently and the average results of samples taken day and night throughout the whole 14-year period gave an effluent with suspended solids of only 7 p.p.m., and 8 p.p.m. of B.O.D., with quite a high nitrate figure. The effect of synthetic detergents had been noticed on 31 March, 1949, when foam had appeared for the first time. Until then, for the whole time the average figure for oxidized nitrogen had been 17 or 18 p.p.m., but in 1950 the concentration of synthetic detergents had reached the point when nitrification had been lost completely, and it had never been recovered.

103. Because the falling-off in performance had occurred at a period of rising load, the usual difficulties had been met in differentiating between the effects of the two factors of loading and synthetic detergents, but the drop in performance appeared far greater than could be attributed to increased loading. Allowing for additional capacity of reserve plant brought into operation, the load on the plant in terms of B.O.D. loading per unit had not been higher than it had previously dealt with successfully for 14 years.

104. Because of the failure of attempts to re-establish nitrification, it was decided in the summer of 1954 to make a number of alterations in plant arrangements so that one of the fifteen units could be entirely isolated, with its final tanks, from the rest of the plant. The sludge had been completely discarded and the plant started afresh to see whether earlier results could be repeated. By September the whole previous experience had been repeated; nitrification had once more been established, with a sludge of good density, and every former benefit of working with nitrification had been obtained. When building up nitrification in an activated-sludge plant in that way it was necessary to nurse the plant first, but once nitrification had been established it was a very robust process, contrary to the Authors' conception of it. When that stage was reached in the experimental unit, the load had been increased until the plant could take no more. That load had been found to be between $70 \%$ and $80 \%-80 \%$ was a generous estimate-of that which could be placed on the plant during the previous 14 years. A drop in efficiency of $20 \%$ required a detention period $25 \%$ longer, and more plant would be required, which at Mogden would cost another $\$ 660,000$. That was the estimate of the damage to that plant alone by synthetic detergents.

105. In making a comparison of that kind, great care had been taken to produce effluents of the same standard of advanced nitrification at a point where ammonia-free conditions had not quite been reached. For Mogden sewage the point was fixed as that where the total oxidized nitrogen was about 10 p.p.m. If the figure should drop to 9 p.p.m. action would be taken to restore it. That was a very accurate method of plant control.

106. Regarding the loss of nitrification on the main plant at Mogden, at first it had been thought that the nitrifying organisms were being inhibited by the synthetic detergents, but later evidence showed that was not so. It was believed that the adverse effects were due mainly to a retardation of the carbonaceous stage to such a degree that if the capacity of the plant did not sufficiently cover the slower rate of purification, the stage of nitrification would not be reached.

107. The Authors stated that they attributed those adverse effects to overloading by carbonaceous material of the alkyl-benzene-sulphonate type, but he did not agree. If there were an increase of loading from oxidizable material presumably there would be an increased oxygen demand, which would be measured in the load on the plant, but that was not so. There was no greater load on Mogden now than before; without detergents there would have been no difficulty, for the capacity was ample. He did not understand why the Authors, who recognized and explained that synthetic detergents caused a depression of oxygen intake and that some materials were more resistant to biological oxidation than others, had not accepted that as the reason. Hammerton had pointed out in 1954 that although it was true that sulphates used in synthetic detergents were usually more amenable to oxidation, and that the sulphonates were more resistant, fundamentally the 
problem could not be explained in that way. Some sulphates, as stated in the introduction were more resistant, and some sulphonates more easily treated; Hammerton's explanation was that it all depended on the structure of the molecule in particular and on whether the chains were straight or branched.

108. The Authors seemed to think that there was a difference between activated sludge and percolating filters in handling synthetic detergents. He stressed that it was possible to run an activated-sludge plant as robustly as a percolating filter; the Authors had produced no evidence that there was a difference in fundamental operation, or in adverse effects of synthetic detergents on that operation, between the two processes.

Dr S. G. Burgess (Scientific Adviser to the London County Council) stated that the Authors' results did not apply exactly to the activated-sludge process; that might be because activated sludge did occlude some synthetic detergent. From some determinations in activated sludge he had found that the synthetic in the sludge was $25-27$ p.p.m. with an influent to the plant of 9.5 p.p.m. and an effluent from it of 6.7 p.p.m. The B.O.D. loading of synthetic detergents depended on whether the detergent had any biological oxygen demand. Several such detergents gave almost a nil result on the 5-day B.O.D. test. Other types became only partially biologically oxidized and lost their surfaceactive properties yet had a very small B.O.D. Therefore the loading, as determined by the B.O.D. test, would not include most of the synthetic detergent and similar resistant chemicals although they might reduce the efficiency of the purification process.

110. In $\$ 17$ the amount of synthetic detergent probably present from a sewage flow in gallons per head per day was calculated. In London, where the figure was 50 g.h.d., the figure for synthetic detergents was about 9.5, which agreed with the Authors' calculation. In $\$ 45$ Lissapol was stated to be a non-foamer. He did not agree, because it could give quite a good foam especially when mixed with sewage effluent. He suggested that the Authors should always write Lissapol $\mathrm{N}$ when that was intended because there was a Lissapol C (sodium oleyl sulphate), Lissapol L.S. (sodium oleyl p-anisidide sulphonate), and Lissapol D (a mixture of cetyl and oleyl sulphates). The Authors had mentioned the importance of determining the type of detergent with which they were working. As was well known, Tide in Britain contained, or had contained, tetrapropylene-benzenesulphonate, but Tide in Canada, according to a recent statement was composed of laurylsulphate; he found that puzzling for he was unaware that lauryl-sulphate was marketed anywhere on a price basis comparable to tetrapropylene-benzene-sulphonate.

111. The Authors stated in $\$ 58$ that "There is no doubt that the alkyl-sulphates are readily available as bacterial food." Both the alkyl-sulphates which they used, the Teepol, and lauryl-sulphate, had quite measurable B.O.D. and were decomposed fairly readily, but had they tried any of the very resistant alkyl-sulphates, such as the 3.5.5. trimethylhexyl-sulphate, or Tergitol 7, diethyltridecyl sulphate, of which $85 \%$ was found present in oxygenated water after 21 days? He did not think that they were marketed in Britain which was fortunate from the point of view of sewage purification. It would be possible to have a very large loading of those compounds in the incoming sewage giving practically no increase in B.O.D.

112. At the L.C.C. Northern Outfall Works experiments were made using a 2,000-gal tank, de-aerating the water, adding a synthetic detergent, and determining the time taken to saturate the water with dissolved oxygen. The experiment was repeated many times and under many conditions it was found that 1 p.p.m. of synthetic detergent increased the time required to saturate that water by about $30 \%$. That decrease in rate of saturation corresponded reasonably to the $25 \%$ decrease in efficiency which $\mathrm{Mr}$ Townend had mentioned. Dr Burgess did not claim that was the explanation, but there might be some connexion between the decrease in efficiency and the decreased oxygen solubility in a given time.

Mr E. H. Lewis-Dale (Civil Engineer, Air Ministry) asked the Authors whether a conclusion could be drawn from research on synthetic detergents, as to what was happening to the thousands of small septic tanks in Britain. An engineer might suppose that the 
position was improved, since anaerobic conditions obtained. Because $10-20 \%$ of the septic tanks were insanitary, and the effluent went into the ground or into a neighbouring stream, conditions might deteriorate as a result of domestic use of synthetic detergents.

114. He was interested in the non-foaming Lissapol, which he thought was Lissapol $\mathbf{N}$. In two experiments it hed seemed to be one of the foaming detergents. Might there have been something else in the sewage which caused it to produce a stable soap film, or was a breakdown in the phenol-ethylene-oxide condensate capable of producing foaming after it had been in the presence of active sewage for quite a long time?

115. Lastly, when marketing materials used as food or drugs, including certain disinfectants, the law required that some indication of their composition be given. $\mathrm{He}$ thought it would be useful if that Act could be extended, or a new Act passed, to extend that requirement to synthetic detergents and possibly to give some warning to the public about their use.

Mr A. T. Gardner (Thomas Hedley \& Co., Ltd) said he thought Durham was the first British university to follow the many American universities in publishing a Paper on the subject on which, even now, so little was known. Was Durham planning any further work?

117. Mr Barden had been brave in suggesting that many British sewage-purification plants were overloaded and that additional load produced a deterioration in perform. ance. He had much sympathy with that conclusion. Additional soap-or urea-would probably have had a similar effect. The apparent loss of Mogden capacity might be more theoretical than real through some of the normal load changing to a form which did not appear in the method of measuring the load. A more readily decomposable synthetic detergent would show more in the measurement of load but it was doubtful if the actual plant capacity would thereby be increased.

118. Mr Barden's graphs on his Warburg apparatus showed that at normal concentrations of active detergent the oxygen uptake was faster than if the detergent was not present. The results of the technique needed to be correlated with those of the Water Pollution Laboratory.

119. The considerable advantage of using acclimatized sludge was of interest.

120. The petroleum and soap and synthetic detergent industry had done much work on various aspects of the properties, use, and destruction of synthetic detergents. The sewage and water chemist had been given methods of detecting fractions of a part per million of active detergents amongst a legion of other materials present in vastly greater quantities. The manufacturer's specialist knowledge of the behaviour of soaps and synthetic detergents was naturally greatest on the right side of the kitchen sink. There was, however, still a lot to discover and they were always ready to help.

Mr W. Fillingham Brown (Consulting Engineer) confirmed Mr Townend's statements on the effects of syndets on an activated-sludge plant. Furthermore, Mr Isaac's statement in his introduction that there was evidence that partially broken-down surfaceactive agents might possibly foam more than the original or final product might explain the experience often obtained on the Maple Lodge Works (when Mr Fillingham Brown had been in charge) of the foam reaching its maximum about half-way round the circuit. It had been quite low at the inlet and at the outlet. They had never found an explanation, but the products might have been partially broken down and therefore more liable to foam.

122. Why did the Authors think the activated-sludge process was more susceptible to the effects of syndets than mere filters? They gave a reason, but had they any positive experimental evidence to show that it was so ? His experience, like that of Mr Townend, had been that in general the activated-sludge process was extremely robust and stable and would deal with most industrial wastes experienced in ordinary sewage equally as well as the filter installations provided that nitrification was well established. It seemed, however, that an activated sludge-plant was affected by syndets, and his experience was 
similar to that of $\mathrm{Mr}$ Townend, that about $20-25 \%$ additional capacity was required to deal with sewage containing the normal proportion of synthetic detergents.

Mr A. Holroyd (Manager, Wolverhampton Sewage Disposal Department) drew attention to an omission. The detailed studies of individual detergents in $\$ 41$ did not include a soap.

124. Before the synthetic-detergent era sewage-plant data and design had only to take into account detergency from soap. Now synthetic detergents had partly displaced soap; therefore it seemed necessary to include soap in such studies as a reference datum wherever possible.

125. It might have been illuminating to have had data given by a soap to compare with that for syndets in Figs 2-5. Did the Authors believe that similar curves for soap would have been horizontal lines over the whole range of concentrations tested ?

126. Special reference was made in $\S 70$ to deterioration above 20 p.p.m. concentration with alkyl-sulphates, and it was suggested that that might result solely from an overloading effect owing to increased concentration of oxidizable carbonaceous matter. The Authors could have obtained additional evidence on the point had soap been included and had it behaved in a similar manner.

127. Such a comparison might not be fair since soluble soaps were precipitated in sewage whilst syndets were not. Recollections of pre-war experience tended to support the opposite view. Soluble soap was certainly transformed almost completely into insoluble soaps, but in those days a high proportion went forward to biological oxidation treatment as a colloidal suspension; those conditions could be simulated in the Authors' tests.

128. If the Authors had any additional data on the comparable behaviour of soap, it would be helpful in assessment of their results.

Mr R. D. Raybould (Wolverhampton Sewage Disposal Department) said it was gratifying that the Authors' results had agreed with those of other workers on both the laboratory and works scale.

130. The results of the Warburg-respirometer experiments were of particular interest since they showed that all syndets could, to some extent, be oxidized biologically. That agreed with findings at Wolverhampton where experience showed that biological plants in first-class order could remove most of the syndet in sewage but that plants in poor order, or overloaded, were much lass effective and allowed relatively large amonnts of syndet to pass into the final effluent.

131. The effect of the residual syndet on flora and fauna of rivers and streams was very important, and small amounts of it had been reported in tap water. Because some part, at least, of syndets could resist treatment in a sewage works, dilution, and natural purification in a river, and treatment in a water works, that illustrated their intractable nature. More work on the nature of those syndet residuals and their effect on river life and potable waters was needed.

132. Foaming was still a problem on sewage works; even where foaming on activatedsludge plants was overcome by increasing the amount of activated sludge the plant efficiency was reduced since much of the oxygen in the air supplied to the plant was used in keeping the extra sludge in good condition.

133. He questioned the statement that the carbonaceous matter in syndets caused overloading of biological systems. As with certain gas-liquor constituents he suggested that it was the intractable nature of the syndet which led to difficulties.

134. The Authors had dismissed too readily the theory of syndets adsorbing on to solid matter. Much syndet was found in crude sludge settled out from Coven Heath crude sewage and because crude sewage containing much syndet rarely foamed, that suggested syndets did at least adsorb on to "dirty" solids. He shared the Authors" opinion that syndets adsorbed on to activated sludge and tended to depress oxygentransfer rates. After adsorption the syndet was slowly oxidized. Whilst syndet had 
been found by the Authors in activated sludge none was found in filter humus sludge. $\mathrm{He}$ thought that that was attributable to the oxidized state of humus sludge and its long sojourn in the filter. Examination of filter slime from the top areas of the filter might have led to different results. If that was so it could be assumed that syndets in filters depressed oxygen-transfor rates there as well as in activated-sludge plants although, as the Authors pointed out, those effects were not serious until a critical concentration of syndet was reached. All available evidence indicated that the critical concentration became lower when the sewage-treatment plant became more overloaded.

135. Finally, there was an error in $\$ 33$. Foam on the Wolverhampton activatedsludge channels was not caused by the wind. Gas liquor in the sewage seemed the main cause of the foam and still atmospheric conditions with no wind seemed to favour the build-up of banks of foam behind obstructions.

Mr D. H. Hughes stated that from the Paper and discussion it seemed that for treatment of liquid sewage containing the quantity of syndets now met, $25 \%$ greater biological treatment capacity might be needed. At Mogden Mr Townend stated that would cost $£ 600,000$, or $8 \mathrm{~s}$ 6d per head for the $1,500,000$ population served. As loan repayment that would represent about $7 \mathrm{~d}$ per head per annum. In addition there would be an extra operating cost of, say, $6 \mathrm{~d}$ per head per annum. The total extra cost of maintaining a well-nitrified effluent might be about ls $1 \mathrm{~d}$ per head per annum. He thought that a small price to pay for the benefits obtained from use of synthetic detergents. It represented about ld on every packet of detergent sold.

137. But that might be only part of the story. Could the Authors say if the effluent, purified from the sewage plant, might later produce problems in the river into which it was discharged? What was the effect on sewage sludge? Had they information to offer on whether synthetic detergents found their way to the digestion plants, and if so, how the digestion and subsequent treatment processes were affected. Any material effects to that side of the sewage-treatment process might increase the cost of dealing with synthetic detergents in the sewage.

Mr Barden, in reply, said that so far as one could gather from what had been said during the discussion the theory of carbonaceous overloading being the chief cause of impairment of filter performance had been found unacceptable, and that depression of oxygen transfer rates was held to be the most likely cause. Lynch and Sawyer ${ }^{25}$ (and possibly also the work of Dr Burgess mentioned in $\S 112$ ) had shown that most detergents, including non-ionics, depressed the rate of solution of oxygen into water. If that was the main factor, how was it reconciled with the generally accepted idea that non-ionics did not impair biological-oxidation processes in any way comparable to anionies?

139. The effect of a detergent on the transfer of oxygen into water was likely to be dissimilar to that on sewage. If, as Dr Burgess said in § 112, 1 p.p.m. increased saturation time by $30 \%$ then surely the concentration found in activated sludge would result in the entire absence of free oxygen.

140. The fact that the Warburg curves had shown no depression in oxygen uptake for concentrations of detergent many times greater than those found in practice was not accepted as evidence, since the agitation in the Warburg was said to be excessively vigorous. $\mathrm{Mr}$ Barden did not consider that to be so.

141. Mr Townend and Mr Fillingham Brown did not agree with the reasons given in $\S 77$ why detergents probably had greater adverse effects on the activated-sludge process than on percolating filters, and had asked for experimental evidence. Degens ${ }^{8}$ had investigated the effect of alkyl-benzene-sulphonate on the diffused-air activated-sludge process. The control pilot plant receiving sewage containing 1 to 6 p.p.m. mixed detergent had given excellent purification, including nitrification. A similar plant dosed with 12.5 p.p.m. alkyl-benzene-sulphonate had given no nitrification, and no free oxygen could be detected in the mixed liquor. High concentrations of the detergent had built up in the sludge which turned darker. Although the activated-sludge process was as robust as the percolating filter it seemed to be more susceptible to impairment by detergent. 
142. In reply to Mr Fillingham Brown's remarks in $\$ 121$, Edwards and Ginn ${ }^{26}$ showed that the adsorption of detergents by sludge was reversible and that fact probably had an important bearing on the stage of purification at which foaming would occur.

143. In reply to $\mathrm{Mr}$ Holroyd the value of including a soap for comparison purposes had been appreciated too late to incorporate it in the filter experiments. However, a sample of sodium oleate had been used in a Warburg test. Oxidation had been by unacclimatized activated sludge and had taken place at only an intermediate rate, being nothing like as rapid as the alkyl-sulphates. Since only one rapid test had been done on a soap, no use had been made of it in drawing conclusions.

144. Had a soap been used in the filter experiment it would no doubt have behaved very similarly to the alkyl-sulphates, as had been illustrated by Degens ${ }^{8}$ in tests on Teepol and activated sludge, in which soap had been added to the control to balance the increased B.O.D. of the Teepol-dosed feed.

145. In reply to Mr Lewis-Dale, the Belgian workers Beaujean and Leclerc, ${ }^{27}$ investigating the effect of detergents on the self-purification of sewage, had concluded: (a) that up to 300 p.p.m. alkyl-benzene-sulphonate had no effect on the anaerobic bacteria, but that 15-60 p.p.m. of that agent inhibited the aerobic bacteria; $(b)$ that lauryl sulphate increased the growth of the anaerobics up to 150 p.p.m., then depressed it, and that up to 300 p.p.m. increased the growth of the aerobic; and (c) that a non-ionic phenol condensate might slightly inhibit the anaerobic organisms.

146. On the above limited evidence it seemed unlikely that detergents would affect the performance of septic tanks.

Mr Isaac, who also replied, said that he wished to emphasize the respective functions of the two Authors. Mr Barden had carried out the experimental work; Mr Isaac had been his supervisor. The conclusions that followed from that experimental work were, therefore, those of Mr Barden and he (Mr Isaac) felt that it was only fair that he should have had a chance to bring them forward. That had been justified by the interesting and valuable discussion that had been provoked.

148. For his part, Mr Isaac felt bound to accept the view, explicitly or implicitly put forward by most speakers, that the deterioration in the biological stages of sewage treatment was due, in large part, to an interference with the uptake of oxygen. The research carried out at the Water Pollution Research Laboratory and that reported by Dr Burgess had demonstrated the very marked effect on oxygen-uptake of quite low concentrations of surface-active agents. In the Warburg respirometer even the alkyl-aryl-sulphonates took up oxygen. That result was not to be directly related to any practical method of sewage treatment, since the agitation in the apparatus was so vigorous, as Mr Gardner had implied.

149. Mr Barden's view of the importance of the carbonaceous nature of the synthetic detergents had not, in Mr Isaac's opinion, been fully appreciated or rebutted. More than one speaker had discussed sewage loading in terms of the 5-day B.O.D. Dr Burgess's remarks and the Warburg results indicated that that was not a satisfactory measure of the extra "load" caused by those agents. It was, indeed, doubtful whether, with the increasing incidence of trade-waste waters in sewage, the 5-day B.O.D. was today a satisfactory criterion of sewage "load" in general.

150. Mr Townend in $\S 103$ had indicated that Mogden was carrying the same B.O.D. load now as earlier, allowance being made for the reserve plant brought into operation. There had been, nevertheless, a serious deterioration in effluent quality. It was clear, therefore, that B.O.D. was not a satisfactory criterion of loading for Mogden. And, since $a$ tree was judged by its fruit, not by the quantity of manure applied to it, it was, a fortiori, unsatisfactory to define "overloading" in terms of the B.O.D. load of the inflow sewage. In Mr Isaac's view, a sewage-treatment plant was "overloaded" if it could not meet, within the allowable limits of deterioration of effluent quality, any reasonable demands made upon it. (It was implicit in Mr Townend's valuable contribution that he considered the domestic discharge of synthetic detergents, of the present kinds and at the present rate, as an unreasonable demand.)

$26+$ 
161. Both Mr Townend and Mr Fillingham Brown had taken the Authors to task for their remark in $\$ 78(d)$ that "it appears likely that the activated-sludge process is more sensitive to synthetic detergents and critical concentrations [of detergents] may be lower." Mr Townend himself had, in $\$ 102$ supported that suggestion-and it was no more. An excellent modern activated-sludge plant had been operating very satisfactorily for 14 years, giving effluents with suspended solids averaging 7 p.p.m., a B.O.D. of 8 p.p.m., and. with 17-18 p.p.m. oxidized nitrogen. Now nitrification could not be achieved and the B.O.D. of the effluent had seriously increased. The Authors did not know of comparable results for biological filters; Mr Raybould in his contribution seemed to support that. Nor did the Authors conceive of an activated-sludge plant, in which nitrification had been established and was being maintained, as anything but an excellent robust process (and that had been demonstrated by its widespread use in the United States for a number of apparently difficult and intractable wastes). But that was begging the question, since a nitrifying plant was in efficient operation and one where nitrification had ceased was not. Unless nitrification could be maintained in activated sludge, its ability to meet "shock" loads was almost destroyed.

152. Mr Isaac was interested to learn that evidence gained at Mogden showed that the loss of nitrification there was due to a retardation of the carbon-oxidation stage and not to inhibition of the nitrifying organisms.

153. Dr Burgess's observations had shown that quite high concentrations of synthetic detergent were occluded by activated sludge. That was important in at least two ways. It served to emphasize one important respect in which activated-sludge treatment differed from normal biological filtration; it essentially involved recireulation, which, on the face of it, offered a greater opportunity for adsorption of the surface-active agent. It also afforded an explanation of Mr Fillingham Brown's observation that foam at Maple Lodge was greatest in the middle of the circuit. Near the inlet the relatively high suspended solids occluded the detergent, which was given up as the solids were broken down. That effect had been demonstrated in the work of Bogan and Sawyer. ${ }^{28}$

154. Mr Isaac agreed with Mr Townend that work in the laboratory could not replace full-scale experiments. It was unfortunate, therefore, that there were not more people like Mr Townend, Dr Burgess, and Mr Raybould who had carried out, as well as they could, controlled experiments on the full scale. If academic investigators, such as the present Authors, provoked more people to do that, the results would prove more valuable-and, to practitioners, more convincing - than Tables of laboratory-derived figures.

155. Mr Isaac regretted that the Authors had not, everywhere, specified Lissapol as Lissapol $N$, and had not described it as a "non-foamer" within inverted commas. Further they should have made it clear in $\$ 58$ that they were referring solely to the alkyl-sulphates tested by them. Mr Isaac was grateful to Dr Burgess for the information he had given on those substances.

156. In reply to Mr Lewis-Dale, Mr Isaac had no idea what effect synthetic detergents had had on septic tanks. It was possible that M. van Beneden, of the Centre Belge d'Etude et de Documentation des Eaux, had done some work on the subject. It seemed quite likely, however, that many septic tanks in Britain were so unsatisfactorily operated that further deterioration would pass relatively unnoticed.

157. Many "non-foaming" agents had been shown to foam while being broken down.

158. Mr Lewis-Dale's suggestion that detergents, as marketed, should carry some indication of their composition was interesting and might be useful. It was likely to be of limited value, however, since the active agents were mixtures, the individual constituents of which differed markedly in their susceptibility to biological degradation.

159. Mr Isaae thanked Mr Raybould for his useful contribution and agreed with his remarks in $\$ 133$. He was grateful for the suggestions contained in $\$ 134$. He regretted the error in $\S 33$.

160. The calculation made by $\mathrm{Mr}$ Hughes was interesting and should assist to bring part of that important question into proper perspective. Mr Hughes had, however, gone to the heart of the matter in $\$ \mathbf{1 3 7}$ and the Authors could not, unfortunately, assess the 
long-term effects of synthetic detergents. Until those were fully known it was possible neither to measure the total cost of using synthetic detergents nor, indeed, to determine whether there were other than economic factors which would transcend mere calculations of cost.

161. In answer to Mr Gardner's question as to future work $\mathrm{Mr}$ Isaac had to say that research on the lines started by $\mathrm{Mr}$ Barden was temporarily in abeyance. In view of $\mathrm{Mr}$ Holroyd's valuable suggestions, that was regrettable. Dr Coackley, Senior Research Assistant in the Rockefeller Team, had found that some of the "pure" agents supplied by the manufacturers proved not to be pure when separated chromatographically. It had been necessary, therefore, to take basic organic substances, and after conversion as necessary, to sulphonate them in the laboratory. In that way it was hoped to obtain pure agents the progress of whose degradation could then be determined chromatographically, using the free acid or the ammonium salts. The degradation was carried out in the Warburg respirometer. Mr Isaac said that that work was actively in progress, but that results could not be expected for some time.

\section{FURTher REFhreñes}

21. W. T. Lockett, "Synthetic detergents in relation to the purification of sewage: experiments and operating experiences at Mogden Works". J. \& Proc. Inst. Sew. Purifn. (To be published.)

22. B. A. Southgate and A. L. H. Gameson, "Recent developments in the control of stream pollution". Surveyor, vol. 115 (1956), p. 349.

23. "Water pollution research, 1955". H.M.S.O., 1956. See p. 17.

24. C. Hammerton, "Synthetic detergents and water supplies". Soc. Wat. Treat. Exam. (To be published.)

25. W. O. Lynch and C. N. Sawyer, "Physical behaviour of synthetic detergents. I. Preliminary studies on frothing and oxygen transfer". Sew. and Indust. Wastes, vol. 26 (1954), p. 1193.

26. G. P. Edwards and M. E. Ginn, "Fundamental study of the effect of synthetic deter. gents on the activated sludge process". Progress Report, June 1952-Oct. 1953. New York University.

27. P. Beaujean and E. Leclerc, "Effect of synthetic detergents on the self-purification of sewage". Bull. Centre Belge d'Etude et Doc. Eaux, vol. 17 (1952), p. 152.

28. R. H. Bogan and C. N. Sawyer, "Biochemical degradation of synthetic detergents. III. Relationships between biologieal degradation and froth resistance". Sew, \& Indust. Wastes, vol, 28 (1956), p. 637. 